\title{
$\mathrm{Ca}\left(\mathrm{Mg}_{1 / 3} \mathrm{Ta}_{2 / 3}\right) \mathrm{O}_{3}$ dielectric thin films: Preparation, structure, mechanical and
}

\section{dielectric properties}

\author{
Runrun Li ${ }^{1,2}$, Jing Zhou ${ }^{1}$, Wen Chen ${ }^{1 *}$, Qi Zhang ${ }^{1,3}$, Yiwang Bao ${ }^{2}$ \\ ${ }^{1}$ State Key Laboratory of Advanced Technology for Materials Synthesis and Processing, School of \\ Materials Science and Engineering, Wuhan University of Technology, Wuhan, 430070, P. R. China \\ ${ }^{2}$ National Key Laboratory of Green Building Materials, China Building Materials Academy, \\ Beijing, 100024, P. R. China \\ ${ }^{3}$ School of Aerospace, Transport and Manufacturing, Cranfield University, Cranfield, Bedfordshire, \\ MK43 0AL, UK \\ *Corresponding author \\ Tel: +86-27-87651107, +86-10-51167676 \\ Fax: +86-27-87760129, +86-10-51167302 \\ E-mail address: chenw@,whut.edu.cn (W.Chen)
}

\begin{abstract}
:
The effect of annealing temperature on the crystallinity, grain size and hence mechanical and dielectric properties of $\mathrm{Ca}\left(\mathrm{Mg}_{1 / 3} \mathrm{Ta}_{2 / 3}\right) \mathrm{O}_{3}$ (CMT) dielectric films were systematically studied. The CMT thin films were fabricated by an aqueous solution-gel technology and exhibited uniform, smooth and dense morphologies. The optimum pyrolysis temperature and time was $550{ }^{\circ} \mathrm{C}$ and 330 s. All the CMT films show a single perovskite phase and the crystallization increases with annealing temperature. The hardness and reduced modulus were effectively enhanced by increasing the annealing temperature, which can be correlated to the crystallinity and densification improvements. Higher elastic recovery was observed for CMT films annealed at higher temperatures indicating less difficult recoveries for those films. We also noticed that the dielectric constants were improved for the samples annealed at higher temperature, which may enable higher performances for future microwave communication electronics.
\end{abstract}

Keywords: CMT thin films; nanoindentation; mechanical property; dielectric property; 


\section{Introduction}

With the rapid developments of communication technologies, the microwave dielectric material $\mathrm{Ca}\left(\mathrm{Mg}_{1 / 3} \mathrm{Ta}_{2 / 3}\right) \mathrm{O}_{3}(\mathrm{CMT})$ has been widely used in communication systems such as sensors, filters, antennas and tunable resonators due to its excellent dielectric properties [1-3]. Moreover, compared with its bulk counterparts, CMT in thin film form is desired for the realization of miniaturized, integrated and lightweight microwave communication electronics.

Several techniques have been demonstrated to fabricate CMT thin films such as magnetron sputtering [4], pulsed laser deposition [5], sol-gel process [6,7] and metal-organic chemical vapor deposition [8]. Among those methods, aqueous solution-gel technology is advantageous over other technologies in terms of low temperature preparation, low cost, environmental benignity and precise control of the chemical composition of thin films, making it a very promising method to produce homogeneous thin films.

Mechanical properties of the CMT thin films are of crucial importance in determining the delamination, cracking and fracture behaviors of the thin film devices [9-11]. Several techniques have been used to characterize the mechanical properties of CMT thin films such as impulse acoustic method [12-14], atomic force microscope [15], Brillouin light scattering [16], micro-beam cantilever deflection technology [17], etc. However, systematic studies of the effect of annealing temperatures on the mechanical and dielectric properties of the CMT thin films have not been reported.

Nanoindentation technique has been widely used to characterize the mechanical properties of ceramic thin films due to its high sensitivity, high resolution and facile operation [18-22]. However, most studies on dielectric thin films were focused on ferroelectric and piezoelectric materials especially the $\mathrm{Ba}_{1-\mathrm{x}} \mathrm{Sr}_{\mathrm{x}} \mathrm{TiO}_{3}$ (BST) systems, while fewer attentions have been paid to CMT thin films. For example, Fang et al. reported the fabrication of $\mathrm{Ba}_{0.7} \mathrm{Sr}_{0.3} \mathrm{TiO}_{3}$ thin films through metalorganic decomposition (MOD) method and investigated the annealing temperature-dependent mechanical properties [23]. The hardness increases from $1.95 \mathrm{GPa}$ at $600{ }^{\circ} \mathrm{C}$ to $2.66 \mathrm{GPa}$ at $800{ }^{\circ} \mathrm{C}$, and the elastic modulus increases from $39.4 \mathrm{GPa}$ at $600{ }^{\circ} \mathrm{C}$ to $80.2 \mathrm{GPa}$ at $800{ }^{\circ} \mathrm{C}$. Jian et al. reported the MOD deposited BST thin films with variable Ba contents [24]. It was noticed that the hardness increases from 1.41 GPa to $1.63 \mathrm{GPa}$ and the elastic modulus increases from $59.4 \mathrm{GPa}$ to $75.9 \mathrm{GPa}$ when the Ba content drops from 0.75 to 0.25 [24]. In this work, nanoindentation was used for the first time to characterize CMT thin films. The mechanical property variations of the CMT thin films were systematically studied using the nanoindentation technique and were found to be closely related to the temperature-induced structural changes. Our work about the influence of annealing temperature on CMT film structure and mechanical properties paves the way in designing high performance dielectric thin films for practical applications.

\section{Experimental procedure}

A homogeneous $\mathrm{Ta}(\mathrm{V})$-peroxo-citrato precursor solution was prepared by an aqueous solution method. $\mathrm{Ta}_{2} \mathrm{O}_{5}(99.9 \%)$ and $\mathrm{KOH}$ (A.R., Shanghai, China) were firstly mixed and annealed at 550 
${ }^{\circ} \mathrm{C}$ for $2 \mathrm{~h}$ in an alumina crucible in air. When cooled down to room temperature, deionized water was used to dissolve the solid product. After filtration, a clear transparent solution was obtained. $\mathrm{HCl}(99.5 \%)$ was added to form white precipitations of hydrous tantalum oxide $\left(\mathrm{Ta}_{2} \mathrm{O}_{5} \cdot n \mathrm{H}_{2} \mathrm{O}\right)$, with the $\mathrm{PH}$ value of the solution kept at 2-3. The precipitation was filtered and washed with deionized water. Finally, it was dissolved in an aqueous solution of citric acid (CA) and $\mathrm{H}_{2} \mathrm{O}_{2}$ (30 wt\%; A. R.) by continuous stirring and heating at $60{ }^{\circ} \mathrm{C}$ to form a transparent, water-soluble $\mathrm{Ta}(\mathrm{V})$-peroxo-citrato precursor complex.

The calcium citrate solution and magnesium citrate solution were synthesized by separately adding calcium carbonate and magnesium carbonate to citric acid solution under continuous stirring and heating at $40{ }^{\circ} \mathrm{C}$. Then, the citrate metal solutions were mixed according to the stoichiometric formula of CMT and concentrated to final concentration of $0.1 \mathrm{M}$ by distillation.

The CMT precursor solutions were deposited by spin coating on the cleaned $\mathrm{Pt} / \mathrm{Ti} / \mathrm{SiO} / \mathrm{Si}(100)$ substrates at $2500 \mathrm{rpm}$ for $30 \mathrm{~s}$, followed by drying at $120^{\circ} \mathrm{C}$ for $120 \mathrm{~s}$ and rapidly heat-treated at $550{ }^{\circ} \mathrm{C}$ for various time from $150 \mathrm{~s}$ to $600 \mathrm{~s}$ to remove organic species. These procedures above were repeated 10 times until the desired thickness was obtained. After deposition, the films were finally annealed at $650{ }^{\circ} \mathrm{C}, 700{ }^{\circ} \mathrm{C}, 750{ }^{\circ} \mathrm{C}$ and $800{ }^{\circ} \mathrm{C}$, respectively. The arrays of platinum dot of $0.5 \mathrm{~mm}$ in diameter were coated on the film surface by using dc sputtering, which are used as top electrodes for dielectric performance measurement.

Thermogravimetric analysis (TGA) and differential scanning calorimetry (DSC) of the dried CMT gel sample was conducted using a STA409 instrument (NETZSCH, Selb). The crystalline structure of the films was determined by X-ray diffraction (XRD) technique (X'pert PRO MPD) using $\mathrm{Cu} K_{\alpha 1}$ radiation in parallel optical mode. The surface and cross-sectional morphologies were characterized by a field emission scanning electron microscope (FE-SEM, JEOL, JSM-6700F, 20KV), a high-resolution transmission electron microscope (HRTEM, JEOL JEM-2010FEF microscope) and an atomic force microscope (AFM, SPI 4000N PROBEATATION \& SPA-300HV SPM UNIT). The X-ray photoelectron spectrum (XPS) measurements were carried out using a PHI Quantum 2000 XPS system with a monochromatic Al K $\alpha$ source and charge neutralizer.

The dielectric properties were measured by an impedance analyzer (HP4294A) ranging from 1 $\mathrm{KHz}$ to $1 \mathrm{MHz}$. The characterization of the mechanical properties of the CMT thin films-substrate system was employed by a nanoindentation (NANOVEA US) with a Berkowich type diamond tip. A holding time of $10 \mathrm{~s}$ was applied when the load was ramped to peak values to avoid possible viscoelastic deformation. Before measurements, the machine compliances and tip area functions of both indenters were precisely calibrated by using a fused silica sample and a poly-fitting formula. When the mechanical properties of CMT thin films were measured, all the indentations should be spaced $500 \mu \mathrm{m}$ apart to prevent adjacent indentation interplaying. At least six indentations should be made to remove contingency.

\section{Results and discussions}

Fig. 1 illustrates the thermal decomposition behavior of the CMT precursor gel. TG and DSC 
analyses were carried out in air at a heating rate of $10{ }^{\circ} \mathrm{C} / \mathrm{min}$. A significant weight loss is observed below $200{ }^{\circ} \mathrm{C}$ on $\mathrm{TG}$ curve due to the evaporation of water and amomonia, relating to two endothermic peaks on DSC curve at $132.0{ }^{\circ} \mathrm{C}$ and $190.4{ }^{\circ} \mathrm{C}$. An exothermic peak at $540.9{ }^{\circ} \mathrm{C}$ appears in the DSC curve, corresponding to the decomposition of the gel network and the change in the metal complexes into their corresponding metal oxide. The highly exothermal decomposition is also accompanied by a rapid weight loss of $30 \%$, implying the complete removal of organic matrix. The weak exothermic peak at $600{ }^{\circ} \mathrm{C}$ on DSC curve is not accompanied by obvious weight loss. This behavior is caused by crystallization of CMT and the formation of a perovskite phase.

Pyrolysis is a very important step in obtaining high quality thin films by aqueous solution-gel methods. The temperature and time used for pyrolysis are critical factors, because the thin film structure and properties such as crystallinity and surface morphology can be significantly affected by the volatilization of organic compounds during pyrolysis. XRD characterization of the films pyrolyzed at $550{ }^{\circ} \mathrm{C}$ for various time is shown in Fig. 2. Weak perovskite phase and a secondary phase are observed in the film pyrolyzed at $550{ }^{\circ} \mathrm{C}$ for $150 \mathrm{~s}$ and $210 \mathrm{~s}$. By increasing time, the CMT thin film pyrolyzed at $550{ }^{\circ} \mathrm{C}$ for $330 \mathrm{~s}$ shows a pure perovskite phase. However, the $\mathrm{MgTa}_{2} \mathrm{O}_{6}$ phase appears again when the time was further increased to $600 \mathrm{~s}$. One possible reason for the formation of this secondary phase is that in the B-site complex perovskite CMT, B-site $\mathrm{Mg}^{2+}$ ion has the similar size and valence state with the $\mathrm{Ca}^{2+}$ ion, so the $\mathrm{Mg}^{2+}$ may enter into the A-site when pyrolysis time is too long or too short, which is undesired for the formation of perovskite CMT.

Effects of annealing temperature on the crystalline structure of the CMT thin films are shown in Fig. 3a. All the CMT thin films are well-crystallized with perovskite structures. No impurity phases were detected except the peaks from Pt substrate. The intensities of diffraction peaks increase at higher annealing temperatures, showing enhanced crystallization. Detailed crystalline structures of the CMT films were further characterized using HRTEM (Fig. 3b). The film was annealed at $700{ }^{\circ} \mathrm{C}$ and shown well-defined lattice fringes. The inset in Fig. $3 \mathrm{~b}$ is an enlarged view of the crystal lattice showing an interspacing distance of $0.276 \mathrm{~nm}$ corresponding to the (112) plane of the perovskite CMT phase.

XPS technique was used to investigate the chemical compositions of the CMT film. Full spectrum of the CMT film annealed at $700{ }^{\circ} \mathrm{C}$ is shown in Fig. 4a, revealing XPS peaks for Ca, $\mathrm{Mg}$, Ta and O. Detailed views of the XPS peaks from different elements are shown in Fig. 4b-e, respectively. The $\mathrm{Ca} 2 \mathrm{p}$ core level XPS spectrum (Fig. 4b) has two peaks at $347.75 \mathrm{eV}(2 \mathrm{p} 3 / 2)$ and $351.29 \mathrm{eV}(2 \mathrm{p} 1 / 2)$, corresponding to the $\mathrm{Ca}-\mathrm{O}$ bond. The $\mathrm{Mg} 1 \mathrm{~s}$ core level spectrum (Fig. 4c) indicates that there is a peak at $1304.73 \mathrm{eV}$, which originates from $\mathrm{Mg}^{2+}$ ion. Fig. $4 \mathrm{~d}$ shows the high resolution XPS spectra of the Ta4f 5/2 and Ta4f 7/2 at the binding energies of 28.49 and $26.56 \mathrm{eV}$, respectively, which is in good agreement with the values for $\mathrm{Ta}^{5+}$ ion [25]. The O1s spectra in Fig. $4 \mathrm{e}$ show that two chemical states of oxygen coexist, and the peak located at $532.75 \mathrm{eV}$ belongs to the $\mathrm{O}^{2-}$, while the peak located at $531.07 \mathrm{eV}$ proves the existence of surface-adsorbed hydroxide $(\mathrm{OH})$, which is physically adsorbed on the surface.

Fig. 5 shows top and cross-sectional SEM images of the CMT thin films annealed at different 
temperatures. Smaller grains were observed for thin films annealed at relatively lower temperatures (Fig. 5a and 5b). Some pores can also be found which might be attributed to the solvent evaporation at low annealing temperature. At higher annealing temperatures, the grain sizes increase and the increased grain sizes fill the pores. The CMT films at higher temperature exhibit a dense, crack free and uniform surface (Fig. 5c and 5d). Fig. 5e is a cross-sectional SEM image of the thin film annealed at $750{ }^{\circ} \mathrm{C}$, revealing a film thickness of $260 \mathrm{~nm}$. Fig. 6 shows the AFM images of CMT homogeneous thin films annealed at different temperatures. As the deposition temperature of CMT films increases from $650{ }^{\circ} \mathrm{C}$ to $800{ }^{\circ} \mathrm{C}$, the root mean square (RMS) surface roughnesses of CMT films are 4.292, 3.702, 3.138 and $1.779 \mathrm{~nm}$, respectively. This phenomenon should also be owing to organic complex decomposition during annealing process, which eliminates the adsorption sites for metal ions. Also, higher temperature enhances the metal ion activity and surface energy.

It has been recognized that mechanical properties play a crucial role in the integration of CMT thin films with substrates in MEMS. However, for anisotropic materials including CMT thin films, the mechanical properties of materials can usually be reflected by the hardness and reduced modulus. The hardness and reduced elastic modulus can be evaluated by the depth-sensing indentation technique developed by Oliver and Pharr [26]. In this technique, a widely used equation for determining the reduced modulus $\mathrm{E}_{\mathrm{r}}$ is given as the following:

$$
E_{r}=\frac{\sqrt{\pi}}{\mathbf{2}} \frac{S}{\sqrt{A}}
$$

where $\mathrm{A}$ is the area of indent at the peak load, and $\mathrm{S}$ is the contact stiffness from the initial slope of the unloading curve. The hardness is commonly defined as the peak load $\left(\mathrm{P}_{\mathrm{m}}\right)$ divided by the area (A) of indent [27]:

$$
H=\frac{P_{m}}{A}
$$

Fig. 7 shows load-displacement curves of CMT thin films annealed at different temperatures. The hardness, indentation modulus, elastic recovery ratio and plasticity index of all CMT films were evaluated based on those measurements. These measured parameters of CMT thin films are summarized in Table 1. The hardness $\mathrm{H}$ increases from $3.5 \mathrm{GPa}$ (at $650{ }^{\circ} \mathrm{C}$ ) to $5.6 \mathrm{GPa}\left(\right.$ at $800{ }^{\circ} \mathrm{C}$ ) and the reduced modulus $\mathrm{E}_{\mathrm{r}}$ increases from $96 \mathrm{GPa}$ (at $650{ }^{\circ} \mathrm{C}$ ) to $133 \mathrm{GPa}$ (at $800{ }^{\circ} \mathrm{C}$ ). It is suggested that the hardness and reduced modulus of CMT thin films depend on their grain sizes and densifications. At higher annealing temperatures, the grain sizes of CMT films grew larger resulting in less grain boundaries and consequently harder films, which is in agreement with previous reports $[28,29]$. It is noticed that the hardness of the CMT thin films shows a dependence on the surface roughness of the films. The CMT thin film annealed at $800{ }^{\circ} \mathrm{C}$ exhibits lower surface roughness and higher hardness as compared to those samples annealed at lower temperature. Based on the XRD and SEM images, we proposed that the improvement of thin film hardness and reduced modulus results from the larger grain sizes and thus higher densifications of the films annealed at higher temperatures. The improved mechanical properties of CMT thin films make them much mechanically robust.

The plasticity index $\left(\mathrm{H} / \mathrm{E}_{\mathrm{r}}\right)$ has been proposed as the key factor to differentiate elastic and 
elastic-plastic behavior of nanocrystalline thin films. In particular, higher value of hardness to reduced modulus implies higher resistance to plastic deformation. A relatively lower value of hardness to reduced modulus for CMT film indicates that more work is consumed in plastic deformation, and large plastic strain is expected when contacting such a material. With the increasing of the annealing temperature, the plasticity index $\left(\mathrm{H} / \mathrm{E}_{\mathrm{r}}\right)$ of CMT thin films increases from 0.036 at $650{ }^{\circ} \mathrm{C}$ to 0.042 at $800{ }^{\circ} \mathrm{C}$, indicating that less work was consumed in plastic deformation.

Meanwhile, load-displacement curves were employed to estimate the percentage of elastic recovery and energy dissipation using elastic recovery work $r_{e}$ and energy dissipation $r_{d}$. It can be defined and calculated by [27]:

$$
\begin{aligned}
& r_{d}=\frac{h_{f}}{h_{m}} \\
& r_{e}=\frac{\left(h_{m}-h_{f}\right)}{h_{m}}
\end{aligned}
$$

where $h_{m}$ and $h_{f}$ are the displacement at the maximum load and residual impression after unloading, respectively. During a cycle of loading and unloading, the total mechanical work from the indenter is transformed into energy dissipation $r_{d}$ (due to plastic deformation and microcracks) and elastic recovery energy $r_{e}$, i.e. $r_{d}+r_{e}=1$. The higher the value of $r_{e}$ is, the greater the elasticity of the film. The values of all CMT thin films annealed at different temperatures are depicted in Table 1. The elastic recovery energy slightly increases with the increase of annealing temperature. This phenomenon can also be attributed to the enhanced crystallization and hence larger grain sizes and higher densifications. The maximum elastic recovery of $63.4 \%$ was observed for CMT thin films annealed at $800{ }^{\circ} \mathrm{C}$.

Fig. 8 shows the effect of the annealing temperature on the dielectric constant and loss tangent of CMT thin films in the frequency range of $1 \mathrm{KHz}-1 \mathrm{MHz}$. The dielectric constants of CMT films show no appreciable dispersion with the frequency variation. In addition, the dielectric constants of CMT films increase from 15.3 to 19.4 while the loss tangent decrease from 0.05 to 0.02 when the annealing temperature is increased from $650{ }^{\circ} \mathrm{C}$ to $800{ }^{\circ} \mathrm{C}$. The frequency dependence of the dielectric constants in CMT thin films has been suggested to be the presence of space charges between the electrodes and the CMT thin films [30, 31]. Characterization in Fig. 8 reveals that the dielectric properties can also be effectively tuned by varying the annealing temperature and hence controlling the crystal structure of the thin films.

\section{Conclusions}

$\mathrm{Ca}\left(\mathrm{Mg}_{1 / 3} \mathrm{Ta}_{2 / 3}\right) \mathrm{O}_{3}$ (CMT) microwave dielectric films were fabricated on $\mathrm{Pt} / \mathrm{Ti} / \mathrm{SiO}_{2} / \mathrm{Si}$ substrates by an aqueous solution-gel technology. The synthesized CMT precursor solutions were stable. The optimum pyrolysis temperature and time was $550{ }^{\circ} \mathrm{C}$ for $330 \mathrm{~s}$. A single perovskite 
phase with dense and uniform morphology was obtained at different annealing temperatures. HRTEM characterization reveals that interplanar spacings are approximately $0.276 \mathrm{~nm}$ corresponding to the (112) plane of CMT thin films. XPS technique further verified the existence and valance states of $\mathrm{Ca}, \mathrm{Mg}$, Ta and $\mathrm{O}$ in the CMT thin films. Mechanical properties of the CMT thin films were characterized by nanoindentation technique, which indicates that the annealing temperature has a significant influence on the hardness and reduced modulus of the CMT thin films. The hardness increases from $3.5 \mathrm{GPa}\left(\right.$ at $650{ }^{\circ} \mathrm{C}$ ) to $5.6 \mathrm{GPa}$ (at $800{ }^{\circ} \mathrm{C}$ ) and the reduced modulus increases from $96 \mathrm{GPa}\left(\right.$ at $650{ }^{\circ} \mathrm{C}$ ) to $133 \mathrm{GPa}\left(\right.$ at $800{ }^{\circ} \mathrm{C}$ ). It is suggested that the hardness and reduced modulus of CMT thin films depend on their grain sizes and densifications. Further characterizations of the CMT dielectric properties reveal that the dielectric constants and dielectric loss can also be effectively tuned by varying the annealing temperature and hence controlling the crystal structure of the thin films. We also noticed that the dielectric constants were increased for the samples annealed at higher temperature, which may enable higher performances for future microwave communication electronics.

\section{Acknowledgements}

This work was financially supported by the National Natural Science Foundation of China (Grant no. 51572205, 51072148, 51102191 and 51472227), the Fundamental Research Funds for the Central Universities of Ministry of Education of China (Grant no. 2012-II-016).

\section{References}

[1] B. D. Lee, H. R. Lee, K. H. Yoon, Y. S. Cho, Microwave dielectric properties of magnesium calcium titanate thin films, Ceram. Int. 31 (2005) 143-146.

[2] X. H. Hao, J. W. Zhai, J. Zhou, X. W. Li, X. W. Song, S. L. An, Enhanced dielectric properties of lead barium zirconate thin films by manganese doping, Appl. Surf. Sci. 256 (2010) 4902-4905.

[3] H. Kagata, K. Junichi, Dielectric properties of Ca-based complex perovskite at microwave frequencies, Jpn. J. Appl. Phys. 33 (1994) 5463-5465.

[4] K. Shibata, F. Oka, A. Ohishi, T. Mishima, I. Kanno, Piezoelectric properties of (K,Na) $\mathrm{NbO}_{3}$ films deposited by RF magnetron sputtering, Appl. Phys. Express 1 (2008) 011501.

[5] S. Yamazoe, Y. Miyoshi, T. Hattori, H. Adachi, T. Wada, Thermal stability of nickel silicide and shallow junction electrical characteristics with carbon ion implantation, Jpn. J. Appl. Phys. 49 (2010) 1-6.

[6] Y. Nakashima, W. Sakamoto, T. Yogo, Processing of highly oriented (K,Na) $\mathrm{NbO}_{3}$ thin films using a tailored metal-alkoxide precursor solution, J. Eur. Ceram. Soc. 31 (2011) 2497-2503.

[7] C. Kang, J. H. Park, D. Shen, H. Ahn, M. Park, D. J. Kim, Growth and characterization of $\left(\mathrm{K}_{0.5}\right.$ $\left.\mathrm{Na}_{0.5}\right) \mathrm{NbO}_{3}$ thin films by a sol-gel method, J. Sol-gel. Sci. Tech. 58 (2011) 85-90. 
[8] Z. Li, J. Ma, X. J. Feng, X. J. Du, W. G. Wang, M. X. Wang, Effect of thermal annealing on the optical and structural properties of $\gamma-\mathrm{Al}_{2} \mathrm{O}_{3}$ films prepared on $\mathrm{MgO}$ substrates by MOCVD, Ceram. Int. 42 (2016) 551-558.

[9] S. Scarle, C. P. Ewels, M. I. Heggie, Simulation of the delamination of thin films, Eur. Phys. J. B 46 (2005) 529-534.

[10]M. H. Zhao, R. Fu, D. Lu, T. Y. Zhang, Critical thickness for cracking of $\mathrm{Pb}\left(\mathrm{Zr}_{0.53} \mathrm{Ti}_{0.47}\right) \mathrm{O}_{3}$ thin films deposited on Pt/Ti/Si(100) substrates, Acta Mater. 50 (2002) 4241-4254.

[11]A. Lee, B. M. Clemens, W. D. Nix, Stress induced delamination methods for the study of adhesion of Pt thin films to Si, Acta Mater. 52 (2004) 2081-2093.

[12]C. Thomsen, H. T. Grahn, J. Tauc, H. J. Maris, Picosecond interferometric technique for study of phonons in the brillouin frequency range, Opt. Commun. 60 (1986) 55-58.

[13]C. Thomsen, H. T. Grahn, H. J. Maris, J. Tauc, Surface generation and detection of phonons by picosecond light pulses, Phys. Rev. B 34 (1986) 4129-4138.

[14]A. Devos, C. Lerouge, Evidence of laser-wavelength effect in picosecond ultrasonics: Possible connection with interband transitions, Phys. Rev. Lett. 86 (2001) 2669-2672.

[15]K. Miyahara, N. Nagashima, T. Ohmura, S. Matsuoka, Evaluation of mechanical properties in nanometer scale using AFM-based nanoindentation tester, Nanostruct. Mater. 12 (1999) 1049-1052.

[16]D. C. Hurley, V. K. Tewary, A. J. Richards, Thin-film elastic-property measurements with laser-ultrasonic SAW spectrometry, Thin Solid Films 398 (2001) 326-330.

[17]F. E. H. Tay, J. A. V. Kan, F. Watt, W. O. Choong, A novel micro-machining method for the fabrication of thick-film SU-8 embedded micro-channels, J. Micromech. Microeng. 11 (2001) 27-32.

[18] V. Kuznetsov, A. H. Zinn, G. Zampardi, S. Haghighi, F. L. Mantia, A. Ludwig, W. Schuhmann, E. Ventosa, Wet nanoindentation of the solid electrolyte interphase on thin film Si electrodes, ACS. Appl. Mater. Inter. 7 (2015) 23554-23563.

[19]R. He, S. Gahlawat, C. F. Guo, S. Chen, T. Dahal, H. Zhang, W. S. Liu, Q. Zhang, E. Chere, K. White, Studies on mechanical properties of thermoelectric materials by nanoindentation, Phys. Status Solidi A 212 (2015) 2191-2195.

[20]B. Boesl, G. R. Bourne, Analysis of thin films exhibiting large plastic deformation during nanoindentation: A modified Winkler approach, J. Mater. Res. 30 (2015) 2055-2063.

[21]J. W. Suk, V. Mancevski, Y. F. Hao, K. M. Liechti, R. S. Ruoff, Fracture of polycrystalline graphene membranes by in situ nanoindentation in a scanning electron microscope, Phys. Status Solidi R 9 (2015) 564-569.

[22]D. Liu, B. Zhou, S. H. Yoon, H. C. Wikle, Y. Q. Wang, M. Park, B. C. Prorok, D. J. Kim, Effects of the structural layer in MEMS substrates on mechanical and electrical properties of $\mathrm{Pb}\left(\mathrm{Zr}_{0.52} \mathrm{Ti}_{0.48}\right) \mathrm{O}_{3}$ films, Ceram. Int. 37 (2011) 2821-2828.

[23]T. H. Fang, W. J. Chang, C. M. Lin, L. W. Ji, Y. S. Chang, Y. J. Hsiao, Effect of annealing on the structural and mechanical properties of $\mathrm{Ba}_{0.7} \mathrm{Sr}_{0.3} \mathrm{TiO}_{3}$ thin films, Mater. Sci. Eng. A 426 
(2006) 157-161.

[24]S. R. Jian, W. J. Chang, T. H. Fang, L. W. Ji, Y. J. Hsiao, Y. S. Chang, Nanomechanical characteristics of $\mathrm{Ba}_{\mathrm{x}} \mathrm{Sr}_{1-\mathrm{x}} \mathrm{TiO}_{3}$ thin films, Mater. Sci. Eng. B 131 (2006) 281-284.

[25]T. Tateishi, Y. Ito, Y. Okazaki, Corrosion resistance of implant alloys in pseudo physiological solution and role of alloying elements in passive film, Mater. Trans. 38 (1997) 78-84.

[26]W. C. Oliver, G. M. Pharr, An improved technique for determining hardness and elastic modulus using load and displacement sensing indentation experiments, J. Mater. Res. 7 (1992) 1564-1583.

[27]Y. W. Bao, W. Wang, Y. C. Zhou, Investigation of the relationship between elastic modulus and hardness based on depth-sensing indentation measurements, Acta Mater. 52 (2004) 5397-5404.

[28]H. Wu, L. Wu, Q. Sun, W. Fei, S. Du, Mechanical properties of sol-gel derived lead zirconate titanate thin films by nanoindentation, Appl. Surf. Sci. 254 (2008) 5492-5496.

[29]J. Schiotz, T. Vegge, F. D. Di Tolla, K. W. Jacobsen, Atomic-scale simulations of the mechanical deformation of nanocrystalline metals, Phys. Rev. B 60 (1999) 11971.

[30]C. Zhou, D. M. Newns, Intrinsic dead layer effect and the performance of ferroelectric thin film capacitors, J. Appl. Phys. 82 (1997) 3081-3088 .

[31]F. C. Kartawidjaja, C. H. Sim, J. Wang, Ferroelectric and dielectric behavior of heterolayered PZT thin films, J. Appl. Phys. 102 (2007) 124102-1-124102-6. 


\section{Captions to table and figures}

Table 1 RMS roughness and mechanical properties for CMT thin film annealed at different temperatures.

Fig. 1 Thermogravimetric (TG)-differential scanning calorimetry (DSC) curves of CMT precursor gel.

Fig. 2 XRD patterns of CMT thin films pyrolyzed at $550{ }^{\circ} \mathrm{C}$ for various time, and annealed at 700 ${ }^{\circ} \mathrm{C}$ for $1 \mathrm{~h}$.

Fig. 3 (a) XRD patterns of CMT thin films pyrolyzed at $550{ }^{\circ} \mathrm{C}$ for 330 s, annealed at different temperatures for $1 \mathrm{~h}$ and (b) HRTEM images of CMT thin films annealed at $700{ }^{\circ} \mathrm{C}$, the inset is an enlarged image of circular A areas.

Fig. 4 High resolution XPS spectra of the CMT film annealed at $750{ }^{\circ} \mathrm{C}$ (a) full spectrum, (b) Ca $2 \mathrm{~d}$, (c) Mg 1s, (d) Ta 4f, and (e) O1s.

Fig. 5 SEM images of CMT thin films annealed at different temperatures (a) $650{ }^{\circ} \mathrm{C}$, (b) $700{ }^{\circ} \mathrm{C}$, (c) $750{ }^{\circ} \mathrm{C}$, (d) $800^{\circ} \mathrm{C}$, and (e) cross-sectional view SEM image of the CMT thin films from Fig. 5(c).

Fig. 6 AFM images of CMT thin films annealed at different temperatures (a) $650{ }^{\circ} \mathrm{C}$, (b) $700{ }^{\circ} \mathrm{C}$, (c) $750{ }^{\circ} \mathrm{C}$, and (d) $800{ }^{\circ} \mathrm{C}$.

Fig. 7 Typical load-unload curves of CMT thin films annealed at different temperatures.

Fig. 8 Dielectric constant (a) and dielectric loss (b) of CMT thin films annealed at different temperatures in the frequency range of $1 \mathrm{KHz}-1 \mathrm{MHz}$. 
Table 1 RMS roughness and mechanical properties for CMT thin film annealed at different temperatures

\begin{tabular}{ccccccccc}
\hline & \multicolumn{4}{c}{ Total ResidualReduced } & \multicolumn{4}{c}{ Elastic } \\
CMT & RMS & depth & depth & modulus Hardness recovery Plasticity \\
film & $\begin{array}{c}\text { roughness } \\
(\mathrm{nm})\end{array}$ & $\begin{array}{c}\mathrm{h}_{\mathrm{m}} \\
(\mathrm{nm})\end{array}$ & $\begin{array}{c}\mathrm{h}_{\mathrm{f}} \\
(\mathrm{nm})\end{array}$ & $\begin{array}{c}\mathrm{E}_{\mathrm{r}} \\
(\mathrm{GPa})\end{array}$ & $\begin{array}{c}\mathrm{H} \\
(\mathrm{GPa})\end{array}$ & $\begin{array}{c}\mathrm{r}_{\mathrm{e}}(\%) \\
\text { ratio }\end{array}$ & $\begin{array}{c}\text { index } \\
\left(\mathrm{H} / \mathrm{E}_{\mathrm{r}}\right)\end{array}$ \\
\hline $650^{\circ} \mathrm{C}$ & 4.292 & 25.80 & 16.25 & 96 & 3.5 & 0.629 & 0.036 \\
$700^{\circ} \mathrm{C}$ & 3.702 & 25.23 & 15.92 & 111 & 4.4 & 0.630 & 0.039 \\
$750^{\circ} \mathrm{C}$ & 3.138 & 24.99 & 15.83 & 120 & 4.9 & 0.633 & 0.041 \\
$800^{\circ} \mathrm{C}$ & 2.779 & 24.84 & 15.75 & 133 & 5.6 & 0.634 & 0.042 \\
\hline
\end{tabular}




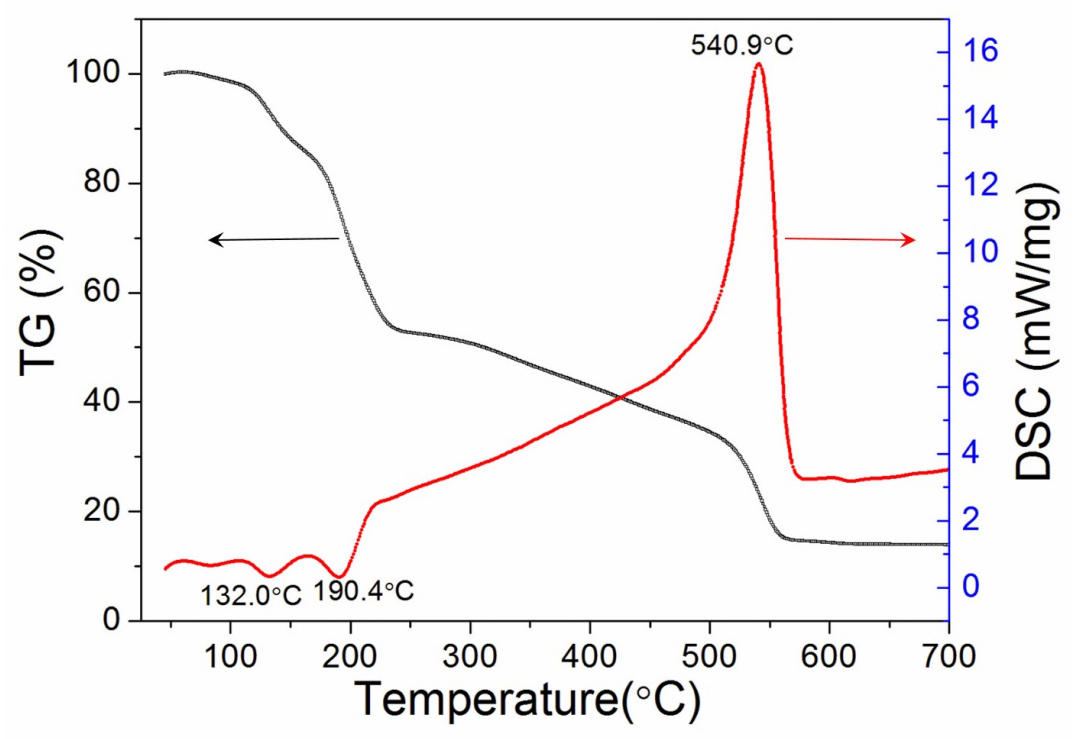

Fig. 1 Thermogravimetric (TG)-differential scanning calorimetry (DSC) curves of CMT precursor gel. 


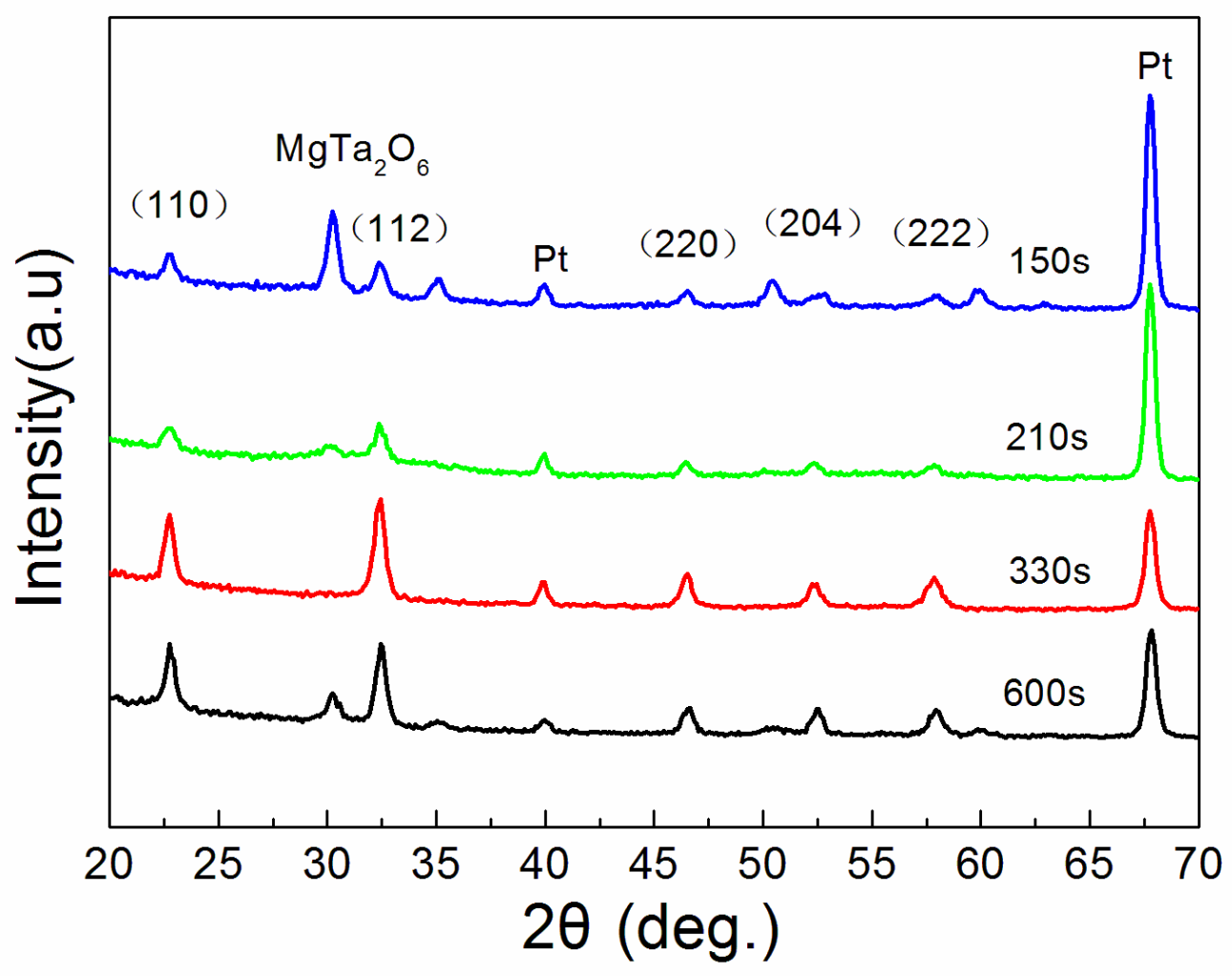

Fig. 2 XRD patterns of CMT thin films pyrolyzed at $550{ }^{\circ} \mathrm{C}$ for various time, and annealed at $700{ }^{\circ} \mathrm{C}$ for $1 \mathrm{~h}$. 

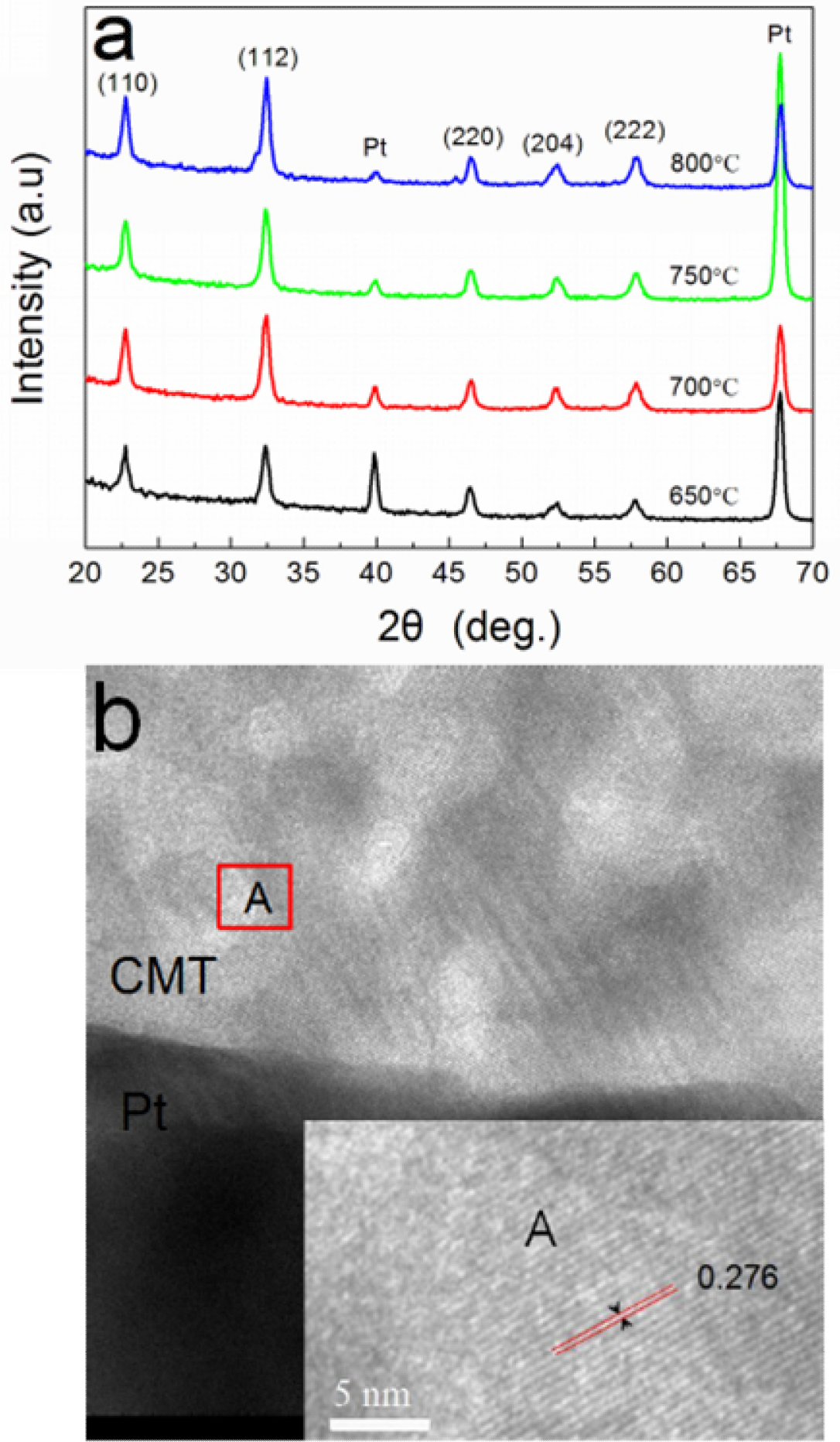

Fig. 3 (a) XRD patterns of CMT thin films pyrolyzed at $550{ }^{\circ} \mathrm{C}$ for $330 \mathrm{~s}$, annealed at different temperatures for $1 \mathrm{~h}$, and (b) HRTEM image of CMT thin films annealed at $700{ }^{\circ} \mathrm{C}$, the inset is an enlarged image of circular A areas. 

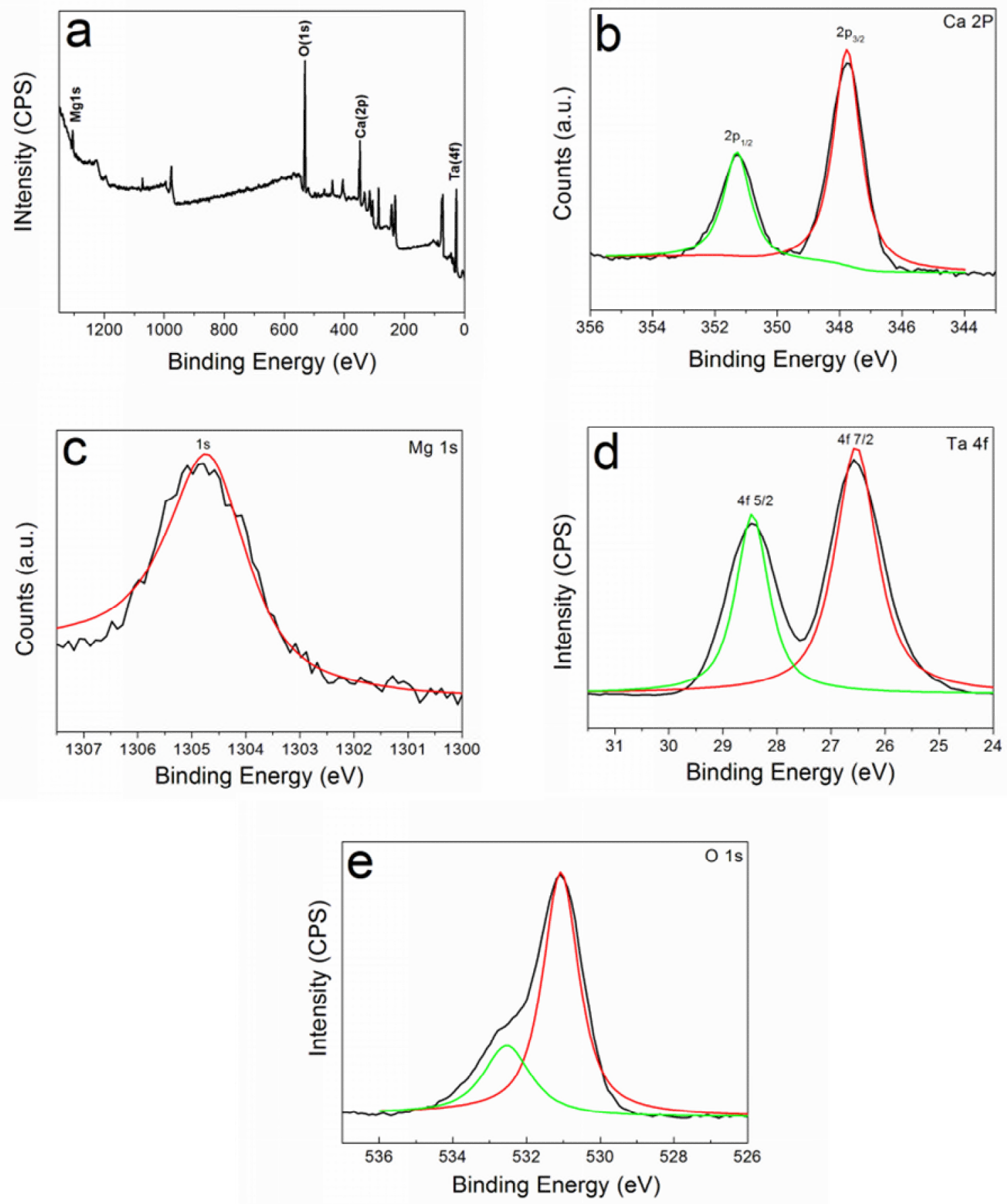

Fig. 4 High resolution XPS spectra of the CMT film annealed at $750{ }^{\circ} \mathrm{C}$ (a) full spectrum, (b) $\mathrm{Ca} 2 \mathrm{~d}$, (c) $\mathrm{Mg} 1 \mathrm{~s}$, (d) Ta 4f, and (e) O1s. 

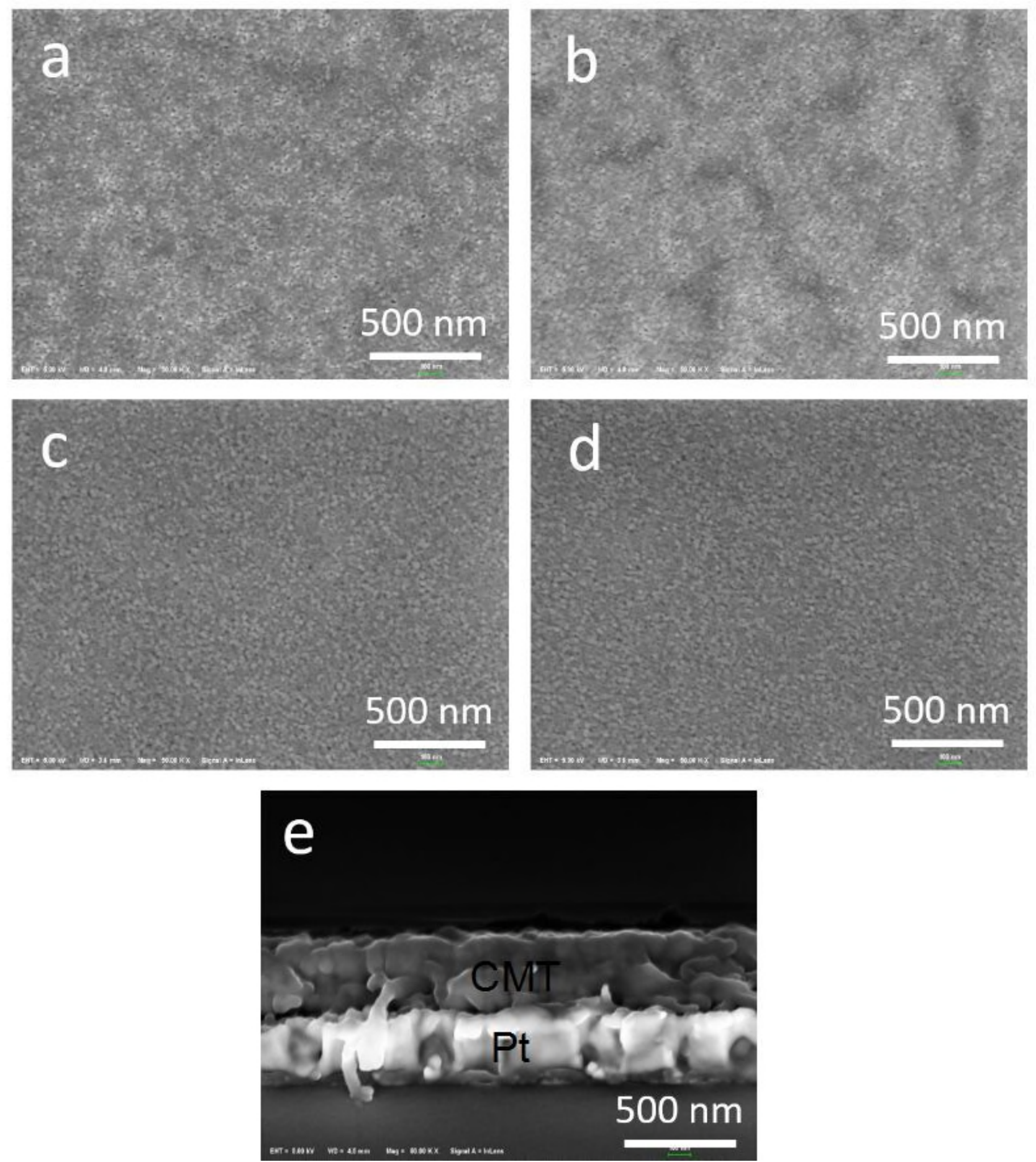

Fig. 5 SEM images of CMT thin films annealed at different temperatures (a) $650{ }^{\circ} \mathrm{C}$, (b) $700{ }^{\circ} \mathrm{C}$, (c) $750{ }^{\circ} \mathrm{C}$, (d) $800^{\circ} \mathrm{C}$, and (e) cross-sectional view SEM image of the CMT thin films from Fig. 5(c). 

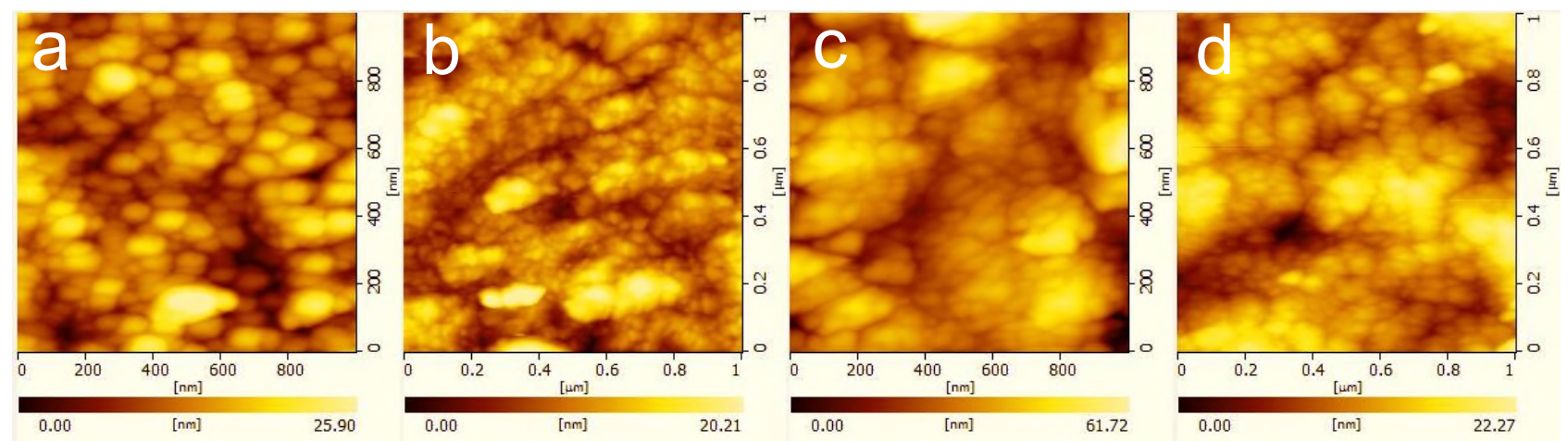

Fig. 6 AFM images of CMT thin films annealed at different temperatures (a) $650{ }^{\circ} \mathrm{C}$, (b) $700{ }^{\circ} \mathrm{C}$, (c) $750{ }^{\circ} \mathrm{C}$, and (d) $800{ }^{\circ} \mathrm{C}$. 


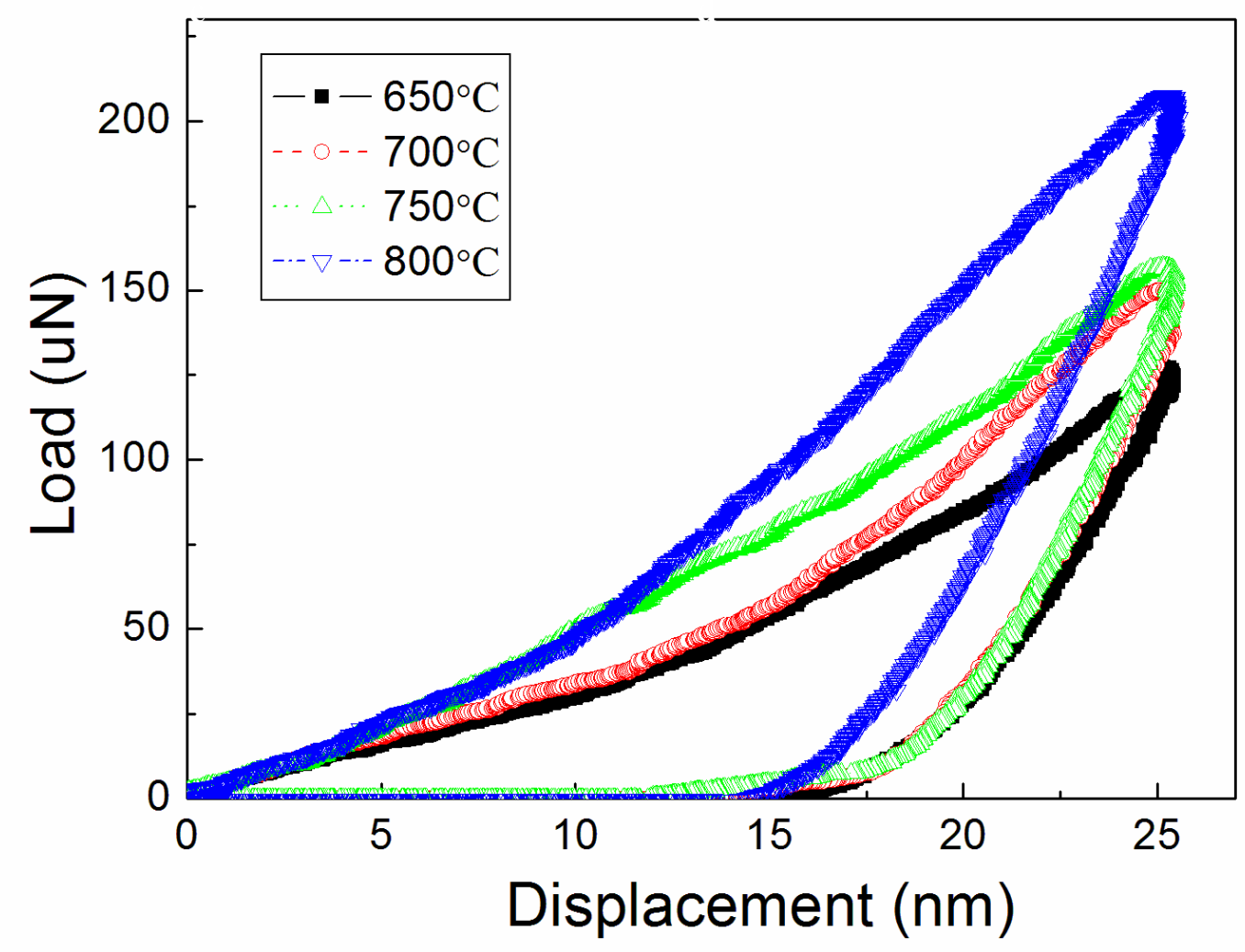

Fig. 7 Typical load-unload curves of CMT thin films annealed at different temperatures. 

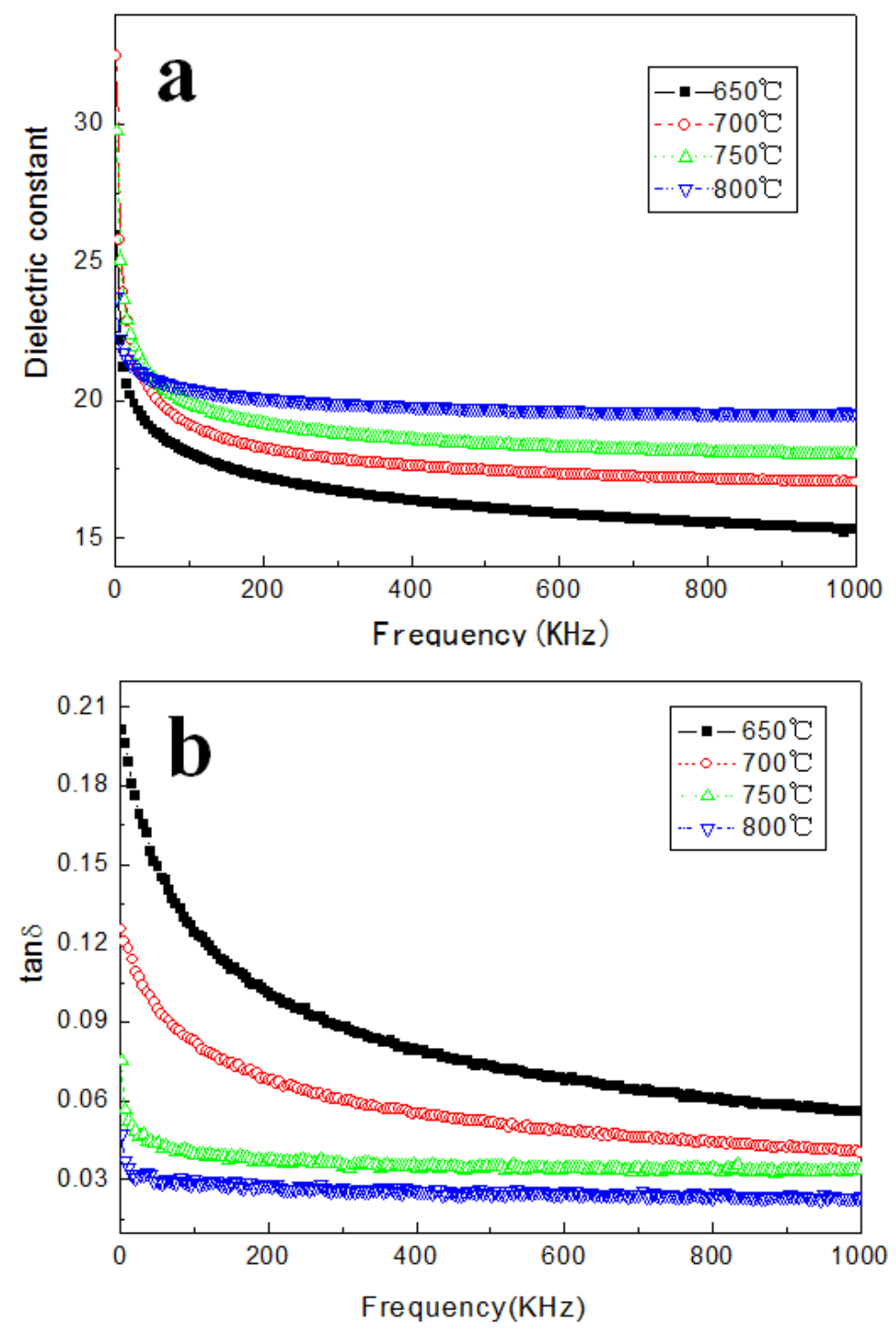

Fig. 8 Dielectric constant (a) and dielectric loss (b) of CMT thin films annealed at different temperatures in the frequency range of $1 \mathrm{KHz}-1 \mathrm{MHz}$. 
2016-05-17

\title{
$\mathrm{Ca}(\mathrm{Mg} 1 / 3 \mathrm{Ta} / 3) \mathrm{O} 3$ dielectric thin films: preparation, structure, mechanical and dielectric properties
}

\author{
$\mathrm{Li}$, Runrun
}

Springer

Runrun Li, Jing Zhou,Wen Chen, Qi Zhang and Yiwang Bao. Ca(Mg1/3Ta2/3)O3 dielectric thin films: preparation, structure, mechanical and dielectric properties. Journal of Materials Science: pÿMaterials in Electronics, 2016, Vol. 27, Iss. 9, pp9391 9397 http://dx.doi.org/10.1007/s10854-016-4982-7

Downloaded from Cranfield Library Services E-Repository 